\title{
Diversidade genética de pacu do Rio Paranapanema e do estoque de um programa de repovoamento
}

\author{
Jayme Aparecido Povh(1), Ricardo Pereira Ribeiro(1), Rodolfo Nardez Sirol(2), Danilo Pedro Streit Júnior(3), \\ Nelson Mauricio Lopera-Barrero(1), Lauro Vargas ${ }^{(1)}$, Patrícia Cristina Gomes ${ }^{(1)}$ e Taís da Silva Lopes $^{(1)}$
}

\begin{abstract}
(1)Universidade Estadual de Maringá, Departamento de Zootecnia, Grupo de Pesquisa PeixeGen, Avenida Colombo, no 5.790, Bloco 111, Sala 6, CEP 87020-900 Maringá, PR. E-mail: jayme.peixegen@gmail.com, rpribeiro@uem.br, nelson.peixegen@gmail.com, Ivargas@uem.br, patriciacristinagomes@hotmail.com, tais.peixegen@gmail.com (2)Duke Energy International Geração Paranapanema S.A., Meio Ambiente, Rodovia Chavantes-Ribeirão Claro, Km 10, CEP 18970-000 Chavantes, SP. E-mail: rnsirol@duke-energy.com (3)Universidade Federal do Rio Grande do Sul, Departamento de Agronomia, Av. Bento Gonçalves, no 7.712, CEP 91540-000 Porto Alegre, RS. E-mail: danilo.streit@ufrgs.br
\end{abstract}

Resumo - O objetivo deste trabalho foi estudar a diversidade genética das amostras de pacu do médio Rio Paranapanema e do estoque de reprodutores utilizado no programa de repovoamento da Estação de Aqüicultura e Hidrologia da usina hidrelétrica Duke Energy, por meio do marcador RAPD. Foram utilizados 14 primers para analisar 30 indivíduos capturados no médio Rio Paranapanema e 29 indivíduos do estoque de reprodutores. O índice de diversidade genética de Shannon e a percentagem de fragmentos polimórficos foram superiores nos indivíduos capturados do Rio Paranapanema. A similaridade genética foi maior nos indivíduos do estoque de reprodutores. A análise da variância molecular mostrou que a maior parte da variação está dentro de cada grupo $(84,2 \%)$ e não entre os grupos (15,8\%). A identidade e distância genética entre os grupos foram 0,9517 e 0,0549, respectivamente. Moderada diferenciação genética $\left(\mathrm{F}_{\mathrm{ST}}=0,15\right)$ e alto número de migrantes por geração $(\mathrm{Nm}=5,33)$ foram observados entre os dois grupos. Há menor diversidade genética do estoque de reprodutores em relação aos indivíduos capturados do Rio Paranapanema.

Termos para indexação: Piaractus mesopotamicus, RAPD, marcador molecular, variabilidade genética.

\section{Genetic diversity of pacu from the Paranapanema River and from the broodstock of a stock enhancement program}

\begin{abstract}
The objective of this work was to study the genetic diversity of pacu samples from the middle Paranapanema River and from the broodstock used in the stock enhancement program of the Aquaculture and Hydrology Station at the Duke Energy Power Plant, by RAPD marker. Fourteen primers were used to analyze 30 individuals captured in the middle Paranapanema River and 29 individuals from the broodstock. The Shannon genetic diversity index and percentage of polymorphic fragments were higher in individuals captured in the Paranapanema River. Genetic similarity was larger in individuals of the broodstock. Results of analysis of molecular variance showed that the major part of the genetic variation is within the groups $(84.2 \%)$ and not between them $(15.8 \%)$. The identity and genetic distance among the groups were 0.9517 and 0.0549 , respectively. Moderate genetic differentiation $\left(\mathrm{F}_{\mathrm{ST}}=0.15\right)$ and high number of migrants per generation $(\mathrm{Nm}=5.33)$ were observed between the two groups. The genetic diversity was lower in the broodstock than in fish captured in the middle Paranapanema River.
\end{abstract}

Index terms: Piaractus mesopotamicus, RAPD, molecular markers, genetic variability.

\section{Introdução}

O Rio Paranapanema é um dos mais importantes afluentes da margem esquerda do Rio Paraná. Tem origem na vertente ocidental da Serra da Paranapiacaba ( $\left.48^{\circ} 15^{\prime} \mathrm{W}, 24^{\circ} 16^{\prime} \mathrm{S}\right)$ no Município de Capão Bonito, SP. Está inserido na Bacia do Alto Paraná, e possui uma extensão de aproximadamente $930 \mathrm{~km}$, dos quais cerca de $330 \mathrm{~km}$ formam a divisa natural entre os estados de São Paulo e Paraná (Britto et al., 2003).

O Rio Paranapanema apresenta 155 espécies de peixes catalogadas, embora muitas raramente sejam encontradas em seu ambiente aquático, como é o caso do Piaractus mesopotamicus (Britto et al., 2003), também conhecido como pacu, caranha, pacu-caranha ou pacu-guaçu. Isso se deve ao fato de que, nos últimos 
50 anos, têm ocorrido impactos negativos na ictiofauna do Rio Paranapanema devido à interferência humana, com a construção de barragem para geração de energia elétrica (10 barragens), poluição dos rios e outras mudanças ambientais (Leuzzi et al., 2004).

Segundo o Ibama (Instituto Brasileiro do Meio Ambiente e dos Recursos Naturais Renováveis), entidades que causam impacto ao ambiente aquático devem adotar medidas de proteção dos recursos biológicos. No entanto, muitas ações que buscam conservar os recursos aquáticos têm sido realizadas sem respaldo científico (Agostinho et al., 2005). Um exemplo são os programas de repovoamento, os quais são muito questionados quanto à sua eficiência e aos impactos que possam causar na ictiofauna.

A diminuição da variabilidade genética reduz a capacidade que os peixes possuem de se adaptarem a diferentes condições ambientais. Portanto, a manutenção da variabilidade genética é importante para a viabilidade dos programas de repovoamento (sobrevivência dos peixes jovens no ambiente), a fim de evitar efeitos adversos na ictiofauna (Barroso et al., 2005; Sirol \& Britto, 2006). Neste contexto, o monitoramento genético desses programas é essencial para a conservação genética. Marcadores moleculares são instrumentos eficientes para este propósito (Sekino et al., 2002; Ortega-Villaizán Romo et al., 2006), e para auxiliar no manejo genético nas pisciculturas de forma a minimizar a endogamia e maximizar a variabilidade genética (Wasko et al., 2004).

O objetivo deste trabalho foi analisar a diversidade genética de P. mesopotamicus do médio Rio Paranapanema e de um estoque de reprodutores utilizado no programa de repovoamento da Estação de Aqüicultura e Hidrologia da usina hidrelétrica Duke Energy, por meio do marcador RAPD.

\section{Material e Métodos}

Foram colhidas 30 amostras de nadadeira caudal de P. mesopotamicus capturados do médio Rio Paranapanema, nas escadas utilizadas para a transposição dos peixes às barragens da usina hidrelétrica Duke Energy, localizadas nos reservatórios Canoas I e Canoas II, nos municípios de Cândido Mota, SP, e Palmital, SP, respectivamente. As capturas foram realizadas em quatro períodos distintos, entre janeiro e fevereiro de 2006.

Quanto ao estoque, 29 amostras de nadadeira caudal foram colhidas de reprodutores de P. mesopotamicus utilizados no programa de repovoamento do Rio Paranapanema pela Estação de Aqüicultura e Hidrologia da usina hidrelétrica Duke Energy, localizada às margens do Rio Paranapanema, em Salto Grande, SP. Os reprodutores apresentavam quatro anos de idade e constituíam um lote de 250 exemplares formados a partir de peixes capturados do Rio Paraná.

A extração de DNA das amostras de fragmentos de nadadeira caudal $\left(0,5 \mathrm{~cm}^{2}\right)$ foi realizada utilizando-se $\mathrm{o}$ método descrito por Bardakci \& Skibinski (1994) modificado por Povh et al. (2005). Os fragmentos de nadadeiras foram colocados em microtubos, aos quais foram adicionados $550 \mu \mathrm{L}$ de tampão de lise $(50 \mathrm{mM}$ de Tris- $\mathrm{HCl}, 50 \mathrm{mM}$ de EDTA, $100 \mathrm{mM}$ de $\mathrm{NaCl}$ e $1 \%$ de SDS ) e $7 \mu \mathrm{L}$ de proteinase $\mathrm{K}\left(200 \mu \mathrm{g} \mathrm{mL}^{-1}\right)$. Em seguida, este material foi incubado em banho-maria a $50^{\circ} \mathrm{C}$ por 4 horas. Posteriormente, o DNA foi purificado com duas extrações com fenol-clorofórmio e posteriormente uma com clorofórmio. O DNA obtido foi precipitado com duas vezes e meia de etanol absoluto e um décimo do volume recuperado de acetato de sódio, e incubado por 1 hora a $-20^{\circ} \mathrm{C}$. O precipitado foi ressuspendido em $100 \mu \mathrm{L}$ de tampão TE (10 mM de Tris e $1 \mathrm{mM}$ de EDTA), e em seguida foi tratado com $6 \mu \mathrm{L}$ de RNAse $\left(30 \mu \mathrm{g} \mathrm{mL}^{-1}\right)$ em banho-maria a $37^{\circ} \mathrm{C}$ por 1 hora. O DNA foi quantificado por comparação com concentrações de DNA fago $\lambda$ conhecidas, em gel de agarose $1 \%$. A eletroforese foi conduzida com tampão 1X TAE ( $40 \mathrm{mM}$ de Tris-acetato e $1 \mathrm{mM}$ de EDTA) por uma hora a 70 volts.

O DNA foi amplificado em um volume de reação de $15 \mu \mathrm{L}$, no qual se utilizou tampão $1 \mathrm{X}$ Tris- $\mathrm{KCl}, 2,0 \mathrm{mM}$ de $\mathrm{MgCl}_{2}, 0,46 \mu \mathrm{M}$ de primer, $0,2 \mathrm{mM}$ de cada dNTP, uma unidade de Taq DNA Polimerase e 10 ng de DNA. Inicialmente o DNA foi desnaturado a $94^{\circ} \mathrm{C}$ por quatro minutos e, em seguida, foram realizados 40 ciclos, cada um com 1 min de desnaturação a $94^{\circ} \mathrm{C}, 1 \mathrm{~min}$ e $30 \mathrm{~s} \mathrm{de}$ anelamento a $40^{\circ} \mathrm{C}$ e 2 min de extensão a $72^{\circ} \mathrm{C}$. Logo depois, realizou-se uma extensão final a $72^{\circ} \mathrm{C}$ por $7 \mathrm{~min}$. As reações foram amplificadas em termociclador Eppendorf Mastercycler Gradient, sendo avaliados 60 primers do Kit OPA, OPX e OPW da Operon (Operon Technologies), dos quais foram selecionados os que apresentaram bandas consistentes e reproduzíveis. A eletroforese foi conduzida em tampão $0,5 \mathrm{X}$ TBE (45 mM de Tris-Borato e $1 \mathrm{mM}$ de EDTA) por 4 horas a 70 volts.

Os géis utilizados na quantificação do DNA e verificação dos produtos de amplifição foram visualizados sob a radiação UV, após exposição ao brometo de etídio $\left(0,5 \mu \mathrm{g} \mathrm{mL}^{-1}\right)$ por 1 hora. Posteriormente, a imagem dos géis foi fotografada com o programa Kodak EDAS-290 (Kodak 1D Image Analysis 3.5). Esse programa foi utilizado para estimar 
o tamanho dos fragmentos amplificados a partir do marcador $100 \mathrm{pb}$ DNA ladder.

A similaridade genética dentro de cada grupo foi obtida com base no cálculo do coeficiente de similaridade de Jaccard, por meio do programa NTSYS 1.7 (Numerical Taxonomy and Multivariate Analysis System) (Rohlf, 1989). O índice de diversidade genética de Shannon foi obtido com o programa PopGene 1.31 (Yeh et al., 1999). O programa TFPGA 1.3 (Miller, 1997) foi utilizado para determinar a percentagem de fragmentos polimórficos (critério de 95\%), distância e identidade genética (Nei, 1978) entre os grupos e frequiência dos fragmentos pelo teste exato (Raymond \& Rousset, 1995).

O programa Arlequin 3.0 (Excoffier et al., 2005) foi utilizado para determinar a diferenciação genética por meio das estimativas de $\mathrm{F}_{\mathrm{ST}}$ (Weir \& Cockerham, 1984), e para análise de variância molecular (AMOVA) (Excoffier et al., 1992). A significância desses testes foi verificada pelo método de permutações aleatórias com 1.000 e 10.000 permutações, respectivamente. Este programa também foi utilizado para determinar o número de migrantes por geração $(\mathrm{Nm})$. A magnitude de diferenciação genética entre os grupos foi determinada segundo a definição de Wright (1978) para caracterizar como baixa $\left(\mathrm{F}_{\mathrm{ST}}=0\right.$ a 0,05$)$, moderada $\left(\mathrm{F}_{\mathrm{ST}}=0,05 \mathrm{a}\right.$ $0,15)$, alta $\left(\mathrm{F}_{\mathrm{ST}}=0,15\right.$ a 0,25$)$ e muito alta $\left(\mathrm{F}_{\mathrm{ST}}>0,25\right)$ a diferenciação genética entre os grupos.

\section{Resultados e Discussão}

Os 14 primers amplificados nas amostras de P. mesopotamicus do estoque de reprodutores e do Rio Paranapanema resultaram em 120 fragmentos (5 a 14 por primer) com tamanho entre 300 e $2.750 \mathrm{pb}$ (Tabela 1).

Tabela 1. Seqüência de nucleotídeos dos primers, número e tamanho dos fragmentos obtidos para as amostras de Piaractus mesopotamicus do Rio Paranapanema e do estoque de reprodutores.

\begin{tabular}{llcc}
\hline Primer & $\begin{array}{c}\text { Seqüência } \\
\left(5^{\prime} \rightarrow 3^{\prime}\right)\end{array}$ & $\begin{array}{c}\text { № de } \\
\text { fragmentos }\end{array}$ & $\begin{array}{c}\text { Tamanho dos } \\
\text { fragmentos }(\mathrm{pb})\end{array}$ \\
\hline OPA01 & CAGGCCCTTC & 8 & $350-1.800$ \\
OPA02 & TGCCGAGCTG & 7 & $300-1.300$ \\
OPA04 & AATCGGGCTG & 8 & $370-1.450$ \\
OPA10 & GTGATCGCAG & 5 & $700-1.500$ \\
OPA16 & AGCCAGCGAA & 14 & $300-2.600$ \\
OPW01 & CTCAGTGTCC & 9 & $400-1.780$ \\
OPW02 & ACCCCGCCAA & 8 & $600-2.500$ \\
OPW03 & GTCCGGAGTG & 11 & $620-2.200$ \\
OPW04 & CAGAAGCGGA & 10 & $530-2.150$ \\
OPW08 & GACTGCCTCT & 8 & $500-1.550$ \\
OPW13 & CACAGCGACA & 6 & $320-2.000$ \\
OPW19 & CAAAGCGCTC & 12 & $380-2750$ \\
OPX01 & CTGGGCACGA & 8 & $520-1.850$ \\
OPX03 & TGGCGCAGTG & 6 & $650-1.820$ \\
\hline Total & & 120 & $300-2.750$ \\
\hline
\end{tabular}

Houve diferença significativa na freqüência de 22 dos 120 fragmentos entre os indivíduos do estoque de reprodutores e do Rio Paranapanema (Tabela 2). Alguns fragmentos foram exclusivos, sendo dois fragmentos no primeiro grupo e quatro fragmentos no segundo grupo. Fragmentos não encontrados nos indivíduos do estoque de reprodutores podem ter sido eliminados na formação deste. A ausência de fragmentos nos indivíduos dos dois grupos pode ser decorrente da origem diferente do primeiro grupo em relação ao segundo (Rio Paraná).

Os indivíduos do estoque de reprodutores e do Rio Paranapanema apresentaram índice de diversidade genética de Shannon de 0,289 e 0,345, respectivamente. A percentagem de fragmentos polimórficos no primeiro grupo foi de 56,36\% e do segundo 61,17\%. Esses resultados, assim como a análise dos fragmentos, mostram menor variabilidade genética no estoque de reprodutores. A maior similaridade genética dos indivíduos do estoque de reprodutores em relação aos do Rio Paranapanema, com valores de 0,840 e 0,779, respectivamente, corroboram a menor variabilidade genética do primeiro grupo.

Segundo Almeida et al. (2003) e Leuzzi et al. (2004), os quais analisaram populações de Pimelodus maculatus e Astyanax altiparanae, respectivamente, do Rio Paranapanema, a diversidade genética varia conforme a espécie, local de captura dos peixes, e das pressões existentes em cada ambiente. Assim, a menor variabilidade genética do estoque de reprodutores neste trabalho pode ser decorrente da diferente origem do estoque em relação aos indivíduos capturados do Rio Paranapanema. Uma investigação sobre diversidade genética da população do Rio Paraná é necessária para verificar tal fato.

Produzir peixes jovens com alta variabilidade genética não depende apenas de um estoque de reprodutores com esta característica. $\mathrm{O}$ inadequado manejo reprodutivo pode promover diminuição da variabilidade genética (Moreira et al., 2007), e em apenas uma geração (Wasko et al., 2004; Porta et al., 2006). A endogamia, a utilização de um pequeno número de reprodutores e a seleção não intencional durante a reprodução (escolha de reprodutores sem pretensões de melhoramento genético, como por exemplo, peixes maiores ou menores e a não utilização de todo o período reprodutivo) são os principais fatores do manejo reprodutivo, que promovem a diminuição da variabilidade genética. A alta prolificidade dos peixes reofílicos, como é o caso da espécie P. mesopotamicus, tende a favorecer fatores do manejo 
reprodutivo que conduzem à diminuição da variabilidade genética, a qual pode ser recuperada com a introdução de novo material genético (Yokota et al., 2003; Sekino et al., 2004). Embora não exista um registro do manejo reprodutivo adotado na formação do estoque de reprodutores, estes fatores podem ter contribuído com a menor variabilidade genética do estoque.

De acordo com a AMOVA, a maior parte da variação está dentro de cada grupo $(84,2 \%)$ e não entre os grupos $(15,8 \%)$ de P. mesopotamicus (Tabela 3). Lopes et al. (2007), após analisarem Salminus brasiliensis capturados das escadas para transposição de peixes das usinas hidrelétricas de Canoas I e Canoas II no Rio Paranapanema, também encontraram maior variância molecular dentro de cada grupo $(98,22 \%)$ do que entre os grupos $(1,78 \%)$. Esses autores observaram baixa diferenciação genética entre estes grupos $\left(\mathrm{F}_{\mathrm{ST}}=0,018\right.$, $\mathrm{p}<0,05)$, alta identidade $(0,985)$ e baixa distância genética $(0,015)$, o que os levaram a concluir que os indivíduos de ambos os grupos estão estruturados geneticamente em uma única população. No entanto, o $F_{\mathrm{ST}}$ de 0,15 $(\mathrm{p}<0,05)$ obtido no presente trabalho indica moderada diferenciação genética entre os grupos segundo a definição de Wright (1978). As estimativas de identidade e distância genética entre os grupos, com valores de 0,9517 e 0,0549 , respectivamente, corroboram esse resultado.

Alta diferenciação genética entre os peixes jovens de um programa de repovoamento e os peixes da população do rio pode caracterizar "pools" de genes distintos, o que pode significar a ausência de genes importantes para adaptação local nos peixes jovens (Almeida et al., 2003; Leuzzi et al., 2004; Vasemägi et al., 2005; Sønstebø et al., 2007). No presente trabalho, os resultados não indicam "pools" de genes muito diferentes entre os dois grupos. Isso é muito importante para um programa de repovoamento, pois um "pool" de genes distinto entre a população do rio e os peixes jovens destinados ao repovoamento poderia significar baixa viabilidade de uso desses peixes.

Tabela 2. Caracterização, tamanho e freqüência dos fragmentos que apresentaram valores significativos pelo teste exato ( $<<0,05$ ) entre as amostras de Piaractus mesopotamicus do Rio Paranapanema e do estoque de reprodutores.

\begin{tabular}{|c|c|c|c|c|}
\hline \multirow[t]{2}{*}{ Primer } & \multirow[t]{2}{*}{ Tamanho (pb) } & \multicolumn{2}{|c|}{ Freqüência dos fragmentos } & \multirow[t]{2}{*}{$\mathrm{p}$} \\
\hline & & Rio Paranapanema & Estoque de reprodutores & \\
\hline OPA01 & 1.800 & 0,2572 & 0,6838 & 0,0010 \\
\hline OPA10 & 1.300 & 0,3333 & 0,8174 & 0,0000 \\
\hline OPA16 & 520 & 0,1502 & 0 & 0,0247 \\
\hline OPA16 & 2.200 & 0,3764 & 0,0513 & 0,0055 \\
\hline OPA16 & 2.300 & 0,3333 & 0,0513 & 0,0085 \\
\hline OPA16 & 2.550 & 0,1181 & 0 & 0,0480 \\
\hline OPW01 & 1.400 & 0,2122 & 0,6349 & 0,0001 \\
\hline OPW01 & 1.600 & 0,0903 & 0,5170 & 0,0000 \\
\hline OPW02 & 600 & 0,1094 & 0 & 0,0098 \\
\hline OPW02 & 1.200 & 0 & 0,5170 & 0,0000 \\
\hline OPW02 & 2.500 & 0 & 0,1244 & 0,0103 \\
\hline OPW03 & 830 & 0,4429 & 1,0000 & 0,0012 \\
\hline OPW03 & 1.250 & 0,5087 & 1,0000 & 0,0042 \\
\hline OPW03 & 1.700 & 0,5087 & 0,8174 & 0,0263 \\
\hline OPW03 & 2.200 & 0,3052 & 0,1244 & 0,0329 \\
\hline OPW08 & 580 & 0,3052 & 0,8174 & 0,0002 \\
\hline OPW13 & 1850 & 0,3732 & 0,8174 & 0,0002 \\
\hline OPW19 & 630 & 0,5000 & 0,7418 & 0,0371 \\
\hline OPX01 & 520 & 0,6078 & 1,0000 & 0,0306 \\
\hline OPX01 & 930 & 0,8039 & 0,3567 & 0,0204 \\
\hline OPX01 & 1.350 & 0,0801 & 0,3052 & 0,0079 \\
\hline OPX01 & 2.000 & 0,1013 & 0 & 0,0245 \\
\hline
\end{tabular}

Tabela 3. Análise de variância molecular (AMOVA) dos grupos de indivíduos da população de Piaractus mesopotamicus do Rio Paranapanema e do estoque de reprodutores.

\begin{tabular}{|c|c|c|c|c|}
\hline Fonte de variação & Graus de liberdade & Soma dos quadrados & Componentes de variação & Percentagem de variação \\
\hline Entre os grupos & 1 & 39,601 & 1,137 & $15,80^{*}$ \\
\hline Dentro dos grupos & 57 & 345,484 & 6,061 & 84,20 \\
\hline Total & 58 & 385,085 & 7,198 & \\
\hline
\end{tabular}

*Significativo a $5 \%$ de probabilidade. 
O número de migrantes por geração $(\mathrm{Nm})$ entre os indivíduos do estoque de reprodutores e do Rio Paranapanema foi de 5,33. Esse valor é alto, considerando que o Rio Paraná está separado do local de captura dos peixes (escadas para transposição de peixes das usinas hidrelétricas de Canoas I e Canoas II - formadas em 1998) pelas barragens das usinas hidrelétricas de Rosana (formada em 1986), Taquaruçu (formada em 1992) e Capivara (formada em 1975), sendo esta última situada à jusante de Canoas I (Britto et al., 2003). Além disso, considerando-se a data de captura das amostras deste trabalho, existem 31 anos de ausência de fluxo gênico natural entre P. mesopotamicus da jusante da barragem de Capivara e dos reservatórios de Canoas I e Canoas II.

Após constatarem um $\mathrm{Nm}$ alto $(2,54)$ entre as populações de Astyanax altiparanae dos reservatórios de Capivara e Jurumirim, no Rio Paranapanema, Leuzzi et al. (2004) sugerem que estes reservatórios tenham sido abastecidos com peixes jovens de procedência comum. Da mesma forma, no presente trabalho, o alto $\mathrm{Nm}$ pode indicar que os indivíduos capturados no Rio Paranapanema sejam provenientes de repovoamento. $\mathrm{O}$ fato de os programas de repovoamento da Estação de Aqüicultura e Hidrologia da usina hidrelétrica Duke Energy (Duke Energy, 2007) e da Secretaria de Estado da Agricultura e Abastecimento do Paraná (Agência Estadual de Notícias, 2007) terem realizado várias solturas de P. mesopotamicus no Rio Paranapanema, corroboram essa disposição. Contudo, uma amostragem mais abrangente de indivíduos de ambos os grupos, assim como a utilização do marcador microssatélite, descrito para essa espécie por Calcagnotto et al. (2001), seria mais adequada para inferir se os peixes capturados do Rio Paranapanema são oriundos de repovoamento.

$\mathrm{O}$ monitoramento genético dos estoques de reprodutores e dos peixes jovens que serão soltos nos rios é fundamental para um programa de repovoamento, tendo em vista que a diminuição da variabilidade genética pode tornar um programa de repovoamento ineficiente, com baixa sobrevivência dos peixes jovens no ambiente, e proporcionar impactos genéticos irreversíveis na população nativa. Contudo, vários fatores que impactam o ecossistema aquático devem ser considerados para que haja sucesso em um programa de repovoamento e não ocorram efeitos adversos na ictiofauna. Dessa forma, medidas conjuntas de conservação da diversidade genética e do ecossistema aquático são necessárias para que esses programas tenham sucesso.

\section{Conclusões}

1. A diversidade genética de Piaractus mesopotamicus é superior nos indivíduos do médio Rio Paranapanema em relação aos do estoque de reprodutores.

2. A diferenciação genética entre P. mesopotamicus do médio Rio Paranapanema e do estoque de reprodutores é moderada.

\section{Referências}

AGÊNCIA ESTADUAL DE NOTÍCIAS. Soltura de peixes nos rios do Paraná. Disponível em: http://www.agenciadenoticias.pr.gov.br. Acesso em: 15 mar. 2007.

AGOSTINHO, A.A.; THOMAZ, S.M.; GOMES, L.C. Conservação da biodiversidade em águas continentais do Brasil. Megadiversidade, v.1, p.70-78, 2005.

ALMEIDA, F.S.; SODRÉ, L.M.K.; CONTEL, E.P.B. Population structure analysis of Pimelodus maculatus (Pisces, Siluriformes) from the Tietê and Paranapanema Rivers (Brazil). Genetics and Molecular Biology, v.26, p.301-305, 2003.

BARDAKCI, F.; SKIBINSKI, D.O.F. Application of the RAPD technique in tilapia fish: species and subspecies identification. Heredity, v.73, p.117-123, 1994.

BARROSO, R.M.; HILSDORF, A.W.S.; MOREIRA, H.L.M.; CABELLO, P.H.; TRAUB-CSEKO, Y.M. Genetic diversity of wild and cultured populations of Brycon opalinus (Cuvier, 1819) (Characiforme, Characidae, Bryconiae) using microsatellites. Aquaculture, v.247, p.51-65, 2005.

BRITTO, S.G.C.; SIROL, R.N.; VIANNA, N.C.; JARDIM, S.M.; SANTOS, J.C.; PELISARI, E. Peixes do rio Paranapanema. São Paulo: Duke Energy, 2003. 112p.

CALCAGNOTTO D.; RUSSELLO, M.; DESALLE, R. Isolation and characterization of microsatellite loci in Piaractus mesopotamicus and their applicability in other Serrasalminae fish. Molecular Ecology Notes, v.1, p.245-247, 2001.

DUKE ENERGY. Meio ambiente. Disponível em: http:// www.duke-energy.com.br/PT/Meioambiente. Acesso em 15 mar. 2007.

EXCOFFIER, L.; LAVAL, G.; SCHNEIDER, S. Arlequin ver. 3.0: an integrated software package for population genetics data analysis. Evolutionary Bioinformatics Online, v.1, p.47-50, 2005.

EXCOFFIER, L.; SMOUSE, P.E.; QUATTRO, J.M. Analysis of molecular variance inferred from metric distances among DNA haplotypes: application to human mitochondrial DNA restriction data. Genetics, v.131, p.479-491, 1992.

LEUZZI, M.S.P.; ALMEIDA, F.S.; ORSI, M.L.; SODRÉ, M.L.K. Analysis by RAPD of the genetic structure of Astyanax altiparanae (Pisces, Characiformes) in reservoirs of the River Paranapanema. Genetics and Molecular Biology, v.27, p.355-362, 2004.

LOPES, C.M.; ALMEIDA, F.S.; ORSI, M.L.; BRITTO, S.G.C.; SIROL, R.N.; SODRÉ, L.M.K. Fish passage ladders from Canoas 
Complex - Paranapanema River: evaluation of genetic structure maintenance of Salminus brasiliensis (Teleostei: Characiformes). Neotropical Ichthyology, v.5, p.131-138, 2007.

MILLER, M.P. Tools for population genetic analyses (TFPGA) 1.3: a Windows program for the analysis of allozyme and molecular population genetic data. Logan: Utah State University, 1997.

MOREIRA, A.A.; HILSDORF, A.W.S.; SILVA, J.V.; SOUZA, V.R. Variabilidade genética de duas variedades de tilápia nilótica por meio de marcadores microssatélites. Pesquisa Agropecuária Brasileira, v.42, p.521-526, 2007.

NEI, M. Estimation of average heterozygosity and genetic distance from a small number of individual. Genetics, v.89, p.583-590, 1978.

ORTEGA-VILLAIZÁN ROMO, M.M.; ARITAKI, M.; TANIGUCHI, N. Pedigree analysis of recaptured fish in the stock enhancement program of spotted halibut Verasper variegates. Fisheries Science, v.72, p.48-52, 2006.

PORTA, J.; PORTA, J.M.; MARTÍNEZ-RODRÍGUEZ, G.; ALVAREZ, M.C. Genetic structure and genetic relatedness of a hatchery stock of Senegal sole (Solea senegalensis) inferred by microsatellites. Aquaculture, v.251, p.46-55, 2006.

POVH, J.A.; MOREIRA, H.L.M.; RIBEIRO, R.P.; PRIOLI, A.P.; VARGAS, L.; BLANCK, D.V.; GASPARINO, E.; STREIT JUNIOR, D.P. Estimativa da variabilidade genética em linhagens de tilápia do Nilo (Oreochromis niloticus) com a técnica de RAPD. Acta Scientiarum: Animal Sciences, v.27, p.1-10, 2005.

RAYMOND, M.; ROUSSET, F. An exact test for population differentiation. Evolution, v.49, p.1280-1283, 1995.

ROHLF, F.J. NTSYS-Pc: numerical taxonomy and multivariate analysis system. New York: Exeter Publishers, 1989.

SEKINO, M.; HARA, M.; TANIGUCHI, N. Loss of microsatellite and mitochondrial DNA variation in hatchery strains of Japanese flounder Paralichthys olivaceus. Aquaculture, v.213, p.101-122, 2002.
SEKINO, M.; SUGAYA, T.; HARA, M.; TANIGUCHI, N. Relatedness inferred from microsatellite genotypes as a tool for broodstock management of Japanese flounder Paralichthys olivaceus. Aquaculture, v.233, p.163-172, 2004.

SIROL, R.N.; BRITTO, S.G. Conservação e manejo da ictiofauna: repovoamento. In: NOGUEIRA, M.G.; HENRY, R.; JORCIN, A. (Ed.). Ecologia de reservatórios: impactos potenciais, ações de manejo e sistemas em cascatas. São Carlos: RiMA, 2006. p.275284.

SØNSTEBØ, J.H.; BORGSTRØM, R.; HEUN, M. Genetic structure of brown trout (Salmo trutta L.) from the Hardangervidda mountain plateau (Norway) analyzed by microsatellite DNA: a basis for conservation guidelines. Conservation Genetics, v.8, p.33-44, 2007.

VASEMÄGI, A.; GROSS, R.; PAAVER, T.; KOLJONEN, M.L.; NILSSON, J. Extensive immigration from compensatory hatchery releases into wild Atlantic salmon population in the Baltic sea: spatiotemporal analysis over 18 years. Heredity, v.95, p.76-83, 2005.

WASKO, A.P.; MARTINS, C.; OLIVEIRA, C.; SENHORINI, J.A.; FORESTI, F. Genetic monitoring of the Amazonian fish matrinchã (Brycon cephalus) using RAPD markers: insights into supportive breeding and conservation programmes. Journal of Applied Ichthyology, v.20, p.48-52, 2004.

WEIR, B.S.; COCKERHAM, C.C. Estimating F statistics for the analysis of population structure. Evolution, v.38, p.1358-1370, 1984.

WRIGHT, S. Evolution and genetics of populations. Chicago: University of Chicago Press, 1978. 511p.

YEH, F.C.; BOYLE, T.Y.Z.; XIYAN, J.M. POPGENE version 131: Microsoft Window-based freeware for population genetic analysis. Edmonton: University of Alberta, 1999.

YOKOTA, M.; HARADA, Y.; IIZUKA, M. Genetic drift in a hatchery and the maintenance of genetic diversity in hatchery-wild systems. Fisheries Science, v.69, p.101-109, 2003.

Recebido em 1ำ de agosto de 2007 e aprovado em 11 de fevereiro de 2008 